Revista de Derecho

\title{
Una actitud posmoderna en relación al derecho (o Eco y Koskenniemi aplicados al Derecho constitucional)
}

\section{A postmodern attitude of Law (Eco and Koskenniemi applied to Constitutional Law)}

\author{
Daniel Eduardo Gallegos Herrera \\ Corte Constitucional del Ecuador \\ dan_gahe@hotmail.com
}

DOI: https://doi.org/10.32719/26312484.2019.31.4

Fecha de recepción: 22 de marzo de 2018

Fecha de aprobación: 26 de febrero de 2019 


\section{RESUMEN}

El artículo propone una actitud posmoderna ante el derecho en general; y, en específico, ante del Derecho constitucional. Con base en la descripción de lo posmoderno de Umberto Eco, identificable como una forma de revisitar el pasado en uso de la ironía, el artículo pasa a identificar cuatro formas de operar en el arte -neoclasicismo, romanticismo, realismo y vanguardismo-, con aproximaciones -regulativa y política- y actitudes -idealista y escéptica- respecto del derecho, que Martti Koskenniemi resalta en su trabajo. El trabajo identifica su propuesta de una cultura de formalismo con la actitud posmoderna consistente en hablar del derecho en la era de la inocencia perdida, y la extiende a un campo distinto a aquel en el que fue gestada: el Derecho constitucional.

Palabras Clave: cinismo, cultura, formalismo, idealismo, ironía, iusnaturalismo, positivismo, posmoderno, realismo, vanguardismo.

\section{ABSTRACT}

In this article it's proposed to take a postmodern attitude toward Law -in generaland specifically toward constitutional law. Based on Umberto Eco's description of the postmodern, identifiable as a way of revisiting the past in use of irony, the article goes on to identify four ways of operating in art: neoclassicism, romanticism, realism and avant-garde, with regulatory and political approximations and idealist and skeptical attitudes, regarding the law, which Martti Koskenniemi highlights in his work. The work identifies his proposal of a culture of formalism with the postmodern attitude of talking about law in the era of lost innocence, and extending it to a field different from the one in which it was conceived: constitutional law.

KEYwORDs: Cynicism, culture, formalism, idealism, irony, natural law, positivism, postmodernism, realism, avant-garde.

\section{INTRODUCCIÓN}

$\mathrm{E}$ 1 presente trabajo parte de la definición de Umberto Eco de lo posmoderno como una forma de operar, por medio del uso de la ironía, para discurrir sobre determinado objeto de forma crítica y despojada de inocencia, pero con el ánimo de reconfigurarlo y no de destruirlo. Con tal objeto, procedo a identificar cuatro períodos artísticos que precedieron al posmodernismo: neoclasicismo, realismo, romanticismo y vanguardismo; los asocio por sus características estéticas y por los ideales en los que se inspiran, con dos aproximaciones y dos actitudes en relación al fenómeno 
jurídico, formuladas por Martti Koskenniemi en lo que considero un trabajo guiado por la actitud posmoderna en relación al Derecho internacional -las aproximaciones regulativa o positivista y la política o realista; y las actitudes idealista y escéptica-. A continuación, efectúo una descripción respecto de la propuesta del autor, consistente en la construcción de una cultura de formalismo, formalismo autorreflexivo, o, como lo denomino en este trabajo, un formalismo en el mundo de la inocencia perdida; así como en su valor como mecanismo para oponerse al poder cuando este utiliza categorías de orden ético o moral para justificar su acción selectiva, opresora y destructiva. Por último, discurro sobre la viabilidad de aplicar el trabajo posmoderno de Koskenniemi a un contexto diferente, como es el de un ordenamiento interno constitucionalizado. A pesar de existir diferencias derivadas de la inexistencia de un solo soberano, de la falta de unidad del ordenamiento, y la ausencia de principios positivados en la norma fundamental, llego a la conclusión de que en el orden interno las condiciones existen para cuestionar, tanto las aproximaciones como las actitudes modernas en relación con el derecho; y que, por tanto, la propuesta consistente en una cultura del formalismo es igualmente viable en el contexto del derecho interno.

\section{LA ACTITUD POSMODERNA EN EL MUNDO DE LAS ARTES}

En su nota al final de El nombre de la rosa, Umberto Eco discurre sobre el posmodernismo, la ironía y lo disfrutable en las artes del siguiente modo:

Desafortunadamente, "posmoderno" es un término à tout faire. Tengo la impresión de que se aplica hoy en día a cualquier cosa que gusta a quien lo usa [...].

En realidad, yo creo que el posmodernismo no es una tendencia que deba ser definida cronológicamente, sino una categoría ideal -o mejor aún, una Kunstwollen, una forma de operar-. [...] Creo que en cada período hay momentos de crisis como aquellos descritos por Nietzsche en sus Consideraciones intempestivas, en que escribió acerca del daño ocasionado por los estudios de la Historia. El pasado nos condiciona, nos hostiga, nos chantajea. El vanguardismo histórico (pero aquí yo también consideraría el vanguardismo una categoría metahistórica) trata de saldar cuentas con el pasado. "Abajo la luz de luna" - un eslogan futurista- es una plataforma típica para todo vanguardismo. Únicamente es necesario reemplazar "luz de luna" con cualquier sustantivo que sea adecuado. El vanguardismo destruye, desfigura el pasado: Las señoritas de la calle Avinyó es un acto típico del vanguardismo. Luego, el vanguardismo va más allá, destruye la figura, la cancela, arriba a lo abstracto, lo informal, el lienzo en blanco, el lienzo acuchillado, el lienzo chamuscado [...].

Pero llega el momento cuando lo vanguardista (lo moderno) no puede ir más allá, pues ha producido un metalenguaje que habla de sus textos imposibles (arte conceptual). La 
Imagen 1. Pablo Picasso, Las señoritas de la calle Avinyó

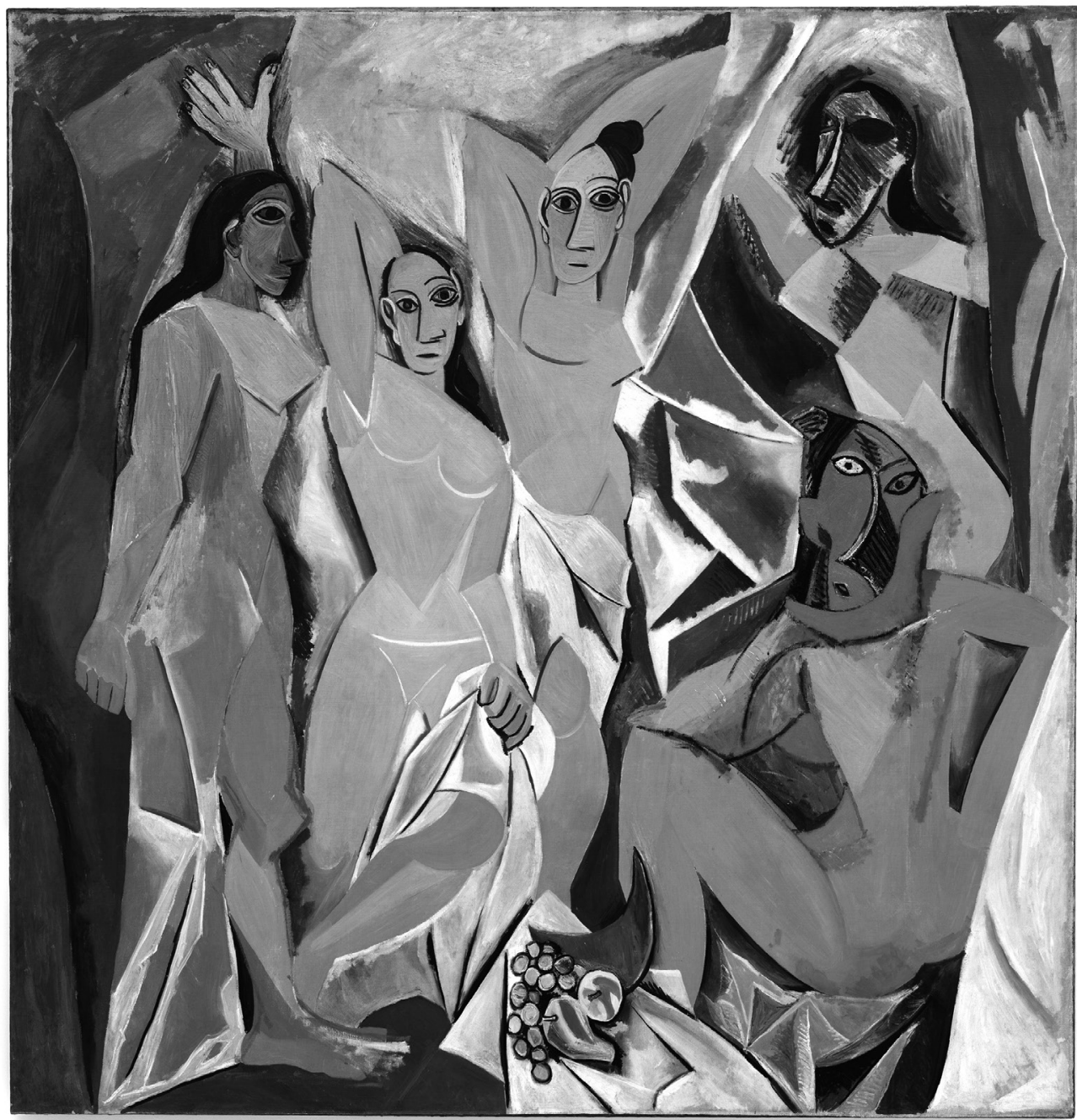

Fuente: Pablo Picasso, "Les Demoiselles d'Avignon”, 1907, óleo sobre lienzo, 244x234 cm, New York, Museo de Arte Moderno, 〈https://en.wikipedia.org/w/index.php?title=File:Les_Demoiselles_d\%27Avignon. jpg\&oldid=783122160>.

respuesta posmoderna a lo moderno consiste en reconocer que como el pasado no puede ser realmente destruido, pues su destrucción lleva al silencio, debe ser revisitado: pero con ironía, no inocentemente. ${ }^{1}$

1. Umberto Eco, The Name of the Rose, trad. por William Weaver (Boston: Houghton Mifflin Harcourt, 
Imagen 2. Juan Antonio de Ribera,

Cincinato abandona el arado para dictar leyes a Roma

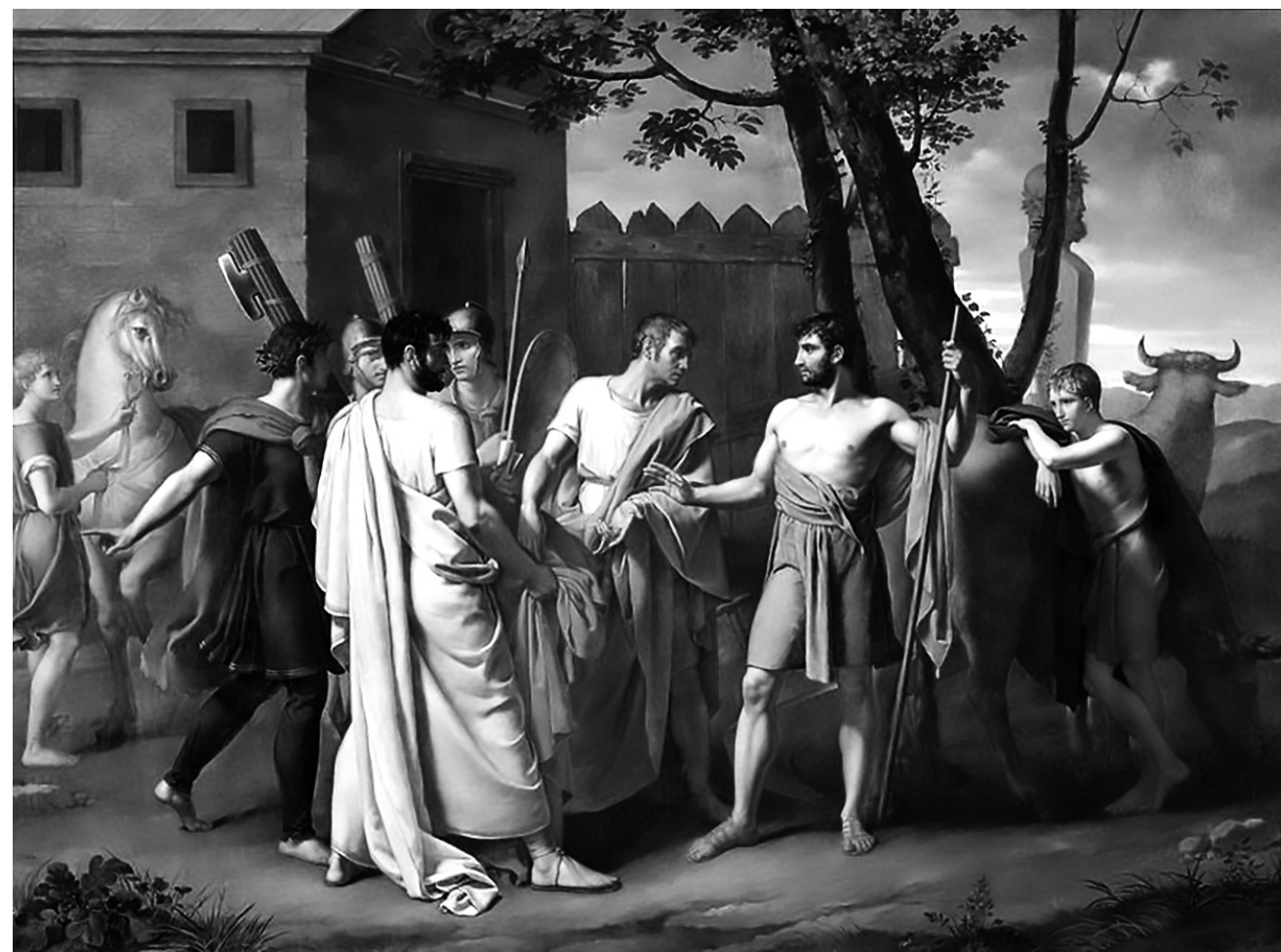

Fuente: Juan Antonio de Ribera, Cincinato abandona el arado para dictar leyes a Roma, 1806, óleo sobre lienzo, 160x215 cm, Madrid, Colección Real del Museo del Prado, 〈https://commons.wikimedia.org/wiki/ File:Cincinato_abandona_el_arado_para_dictar_leyes_a_Roma,_c.1806_de_Juan_Antonio_Ribera.jpg).

Eco identifica la actitud vanguardista con la destrucción, desfiguración. Así, es posible identificar al vanguardismo con ruptura y negación del pasado; las cuales, llevadas al extremo, equivalen al silencio y la nada -nihilismo pasivo, si se quiere trasladar la reflexión al plano filosófico-.

Si seguimos con Eco y su ejemplo de Las señoritas de la calle Avinyó, podemos comprender el sentido en el cual lo entiende como vanguardista. Semenzato se refiere a la pintura de Picasso como una ruptura en la propia obra del autor. "Esta pintura tes-

2011), 〈http://banq.lib.overdrive.com/ContentDetails.htm?id=DA9EF467-F633-4484-8023-B4B0121CD78C >. Edición para Kindle. 
Imagen 3. Eugène Delacroix, La libertad guiando al pueblo

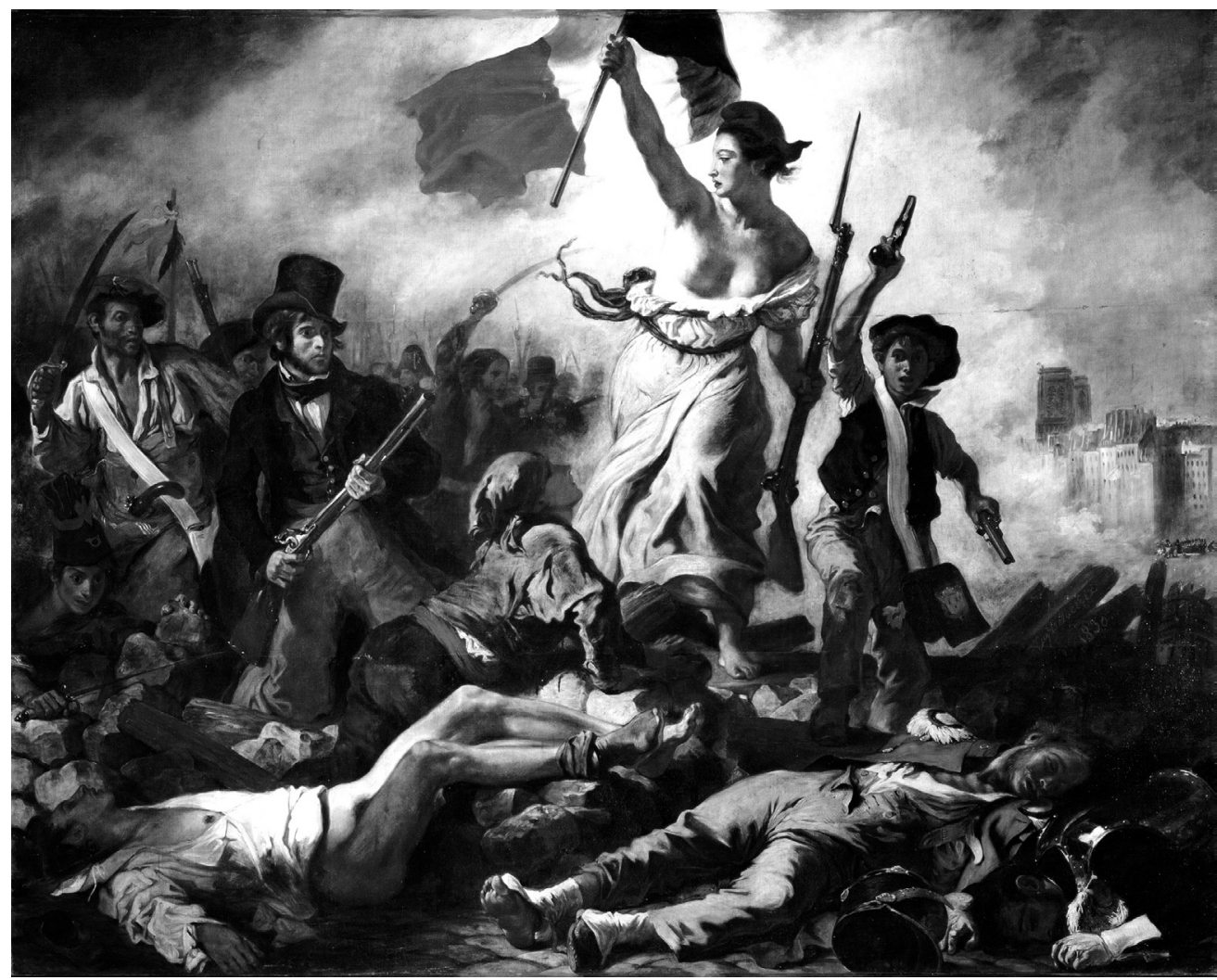

Fuente: Eugène Delacroix, La liberté guidant le peuple, 1830, óleo sobre lienzo, 260×325 cm, París, Museo del Louvre, «https://commons.wikimedia.org/wiki/File:Eug\%C3\%A8ne_Delacroix_-_Le_28_Juillet._La_ Libert\%C3\%A9_guidant_le_peuple.jpg>.

timonia el inicio de la actividad cubista del artista y sobre todo manifiesta el abandono del período propiamente naturalista en favor de una pintura de carácter polémico, provocativa y decididamente contraria a toda concesión idealizante". ${ }^{2}$ Más aún, al indagar sobre el contexto histórico de la pintura, podemos ver que el pasado, en tanto objeto de destrucción, desfiguración, ruptura y negación, más allá de las siluetas de las mujeres que pintó Picasso -y su propio pasado como artista-, es el movimiento del

2. Camillo Semenzato, El mundo del arte (Barcelona: Grijalbo, 1978), 478. 


\section{Imagen 4. Gustave Courbet,}

\section{Hombre desesperado}

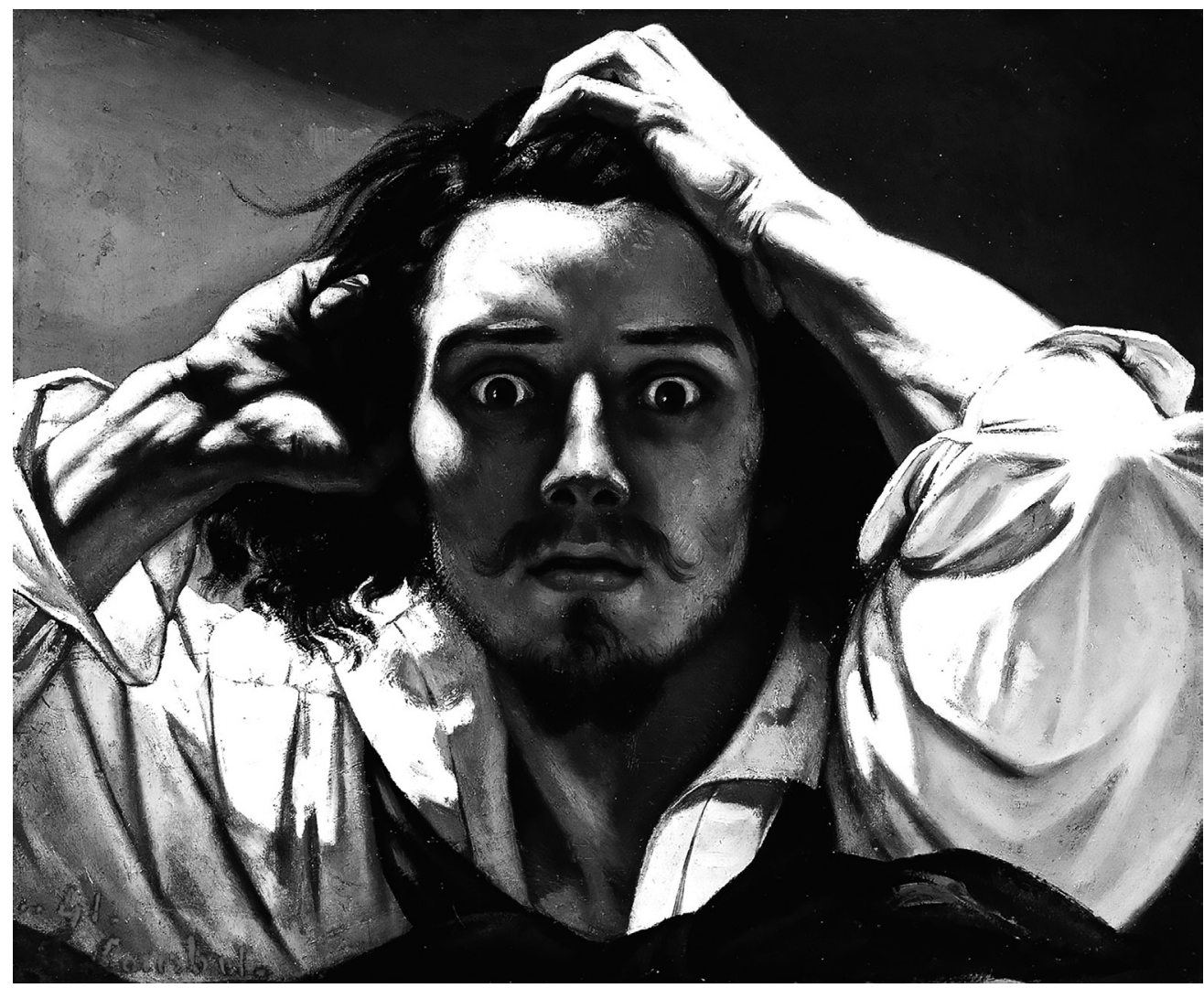

Fuente: Gustave Courbet, Hombre desesperado, circa de 1843, óleo sobre lienzo, $45 \times 54 \mathrm{~cm}$. Colección privada, 〈https://commons.wikimedia.org/wiki/File:Gustave_Courbet_-_Le_D\%C3\%A9sesp\%C3\%A9r\%C3\%A9. JPG .

realismo y todos los movimientos artísticos que vinieron antes, como el romanticismo y el neoclacisismo. ${ }^{3}$

El período neoclásico se halla imbuido por los ideales del Iluminismo y la fuga hacia la antigüedad clásica en búsqueda de modelos, tanto estéticos como ético-políticos -representados en la imagen de Cincinato abandona el arado para dictar leyes a Roma, tanto por la configuración estética de la figura, como en la opción política de Cincinato

3. Ibíd., 406-27. 
en pro del servicio a la República- ${ }^{4}$ El romanticismo, en cambio, apela a la fuerza de las emociones, al mito y la fantasía, y plantea la fuga a la Edad Media -en la segunda imagen, estos elementos hallan su expresión estética en la representación antropomorfa de La Libertad, guiando al pueblo 5 para destacar los ideales de la Revolución francesa-.

Por su parte, el realismo identifica arte y realidad, y halla su base en las simientes del socialismo que se gestaba a mediados del siglo XIX - en la tercera imagen, visible tanto en el esfuerzo de Courbet en presentar a detalle la imagen del Hombre desesperado, como en su propio anonimato y en la cotidianidad de la expresión mostrada- ${ }^{6}$

Así, el vanguardismo representa ruptura, tanto de la representación de la razón como del mito y de la realidad. La ruptura que propone el vanguardismo, llevada al extremo, no deja más que el inmovilismo y la imposibilidad de generar propuestas más allá de la descripción conceptual de la dificultad de establecer propuesta alguna. La siguiente imagen, que presenta la obra de arte conceptual Ampliación fotográfica montada de la definición del diccionario de «definition», permite ilustrar esta aserción.

Volviendo a Eco, el autor propone una actitud posmoderna, identificable con el concepto de ironía. Esta actitud nace en la imposibilidad de mostrarse inocente -esto es, no reconocer la ruptura operada por el vanguardismo respecto de todo lo que sucedió detrás; $\mathrm{y}$, por tanto, mantenerse en una suerte de negación-, y la decisión de no fingir inocencia ante un auditorio que, al igual que el emisor del mensaje, ha experimentado la ruptura. Por otro lado, la actitud posmoderna no busca la destrucción del pasado, sino su revisión; o, si se quiere, su deconstrucción.

El ánimo irónico y deconstructivo que guía la actitud posmoderna es el de no desconocer el pasado, pero no quedarse en él. En ese sentido, se asemeja a la expresión de Christian Deschamps: "déconstruire n'est pas détruire". ${ }^{7}$ La forma de operar en el mundo de la inocencia perdida, entonces, demanda una actitud epistemológica crítica y abierta en sí misma a la crítica, pero siempre orientada a usar el pasado en la búsqueda de que la crítica produzca algo nuevo, distinto, una alternativa entre muchas otras posibles. Eco lo pone del siguiente modo:

[Pienso en la actitud posmoderna como aquella de un hombre que ama a una mujer muy culta y sabe que no puede decirle "te amo locamente", pues sabe que ella sabe (y que ella

4. Semenzato, El mundo del arte, 406.

5. Ibíd., 420. El autor señala: “[a] la Europa neoclásica sucedió la Europa Romántica, los ideales de la razón eran reemplazados por los del sentimiento, el anhelo de libertad de las naciones y de las clases oprimidas, traicionado por el utópico iluminismo que se había chocado con la realidad histórica, intentaba reponerse por el valor que se necesitaba en la conspiración”.

6. Semenzato, El mundo del arte, 424-5.

7. Christian Descamps, Quarante ans de philosophie en France: la pensée singulière, de Sartre à Deleuze, Philosophie présente (París: Bordas, 2003), 130. 


\section{Imagen 5. Joseph Kosuth - Titled (Art as Idea as Idea) The Word "Definition" Ampliación fotográfica montada de la definición del diccionario de "definition"}

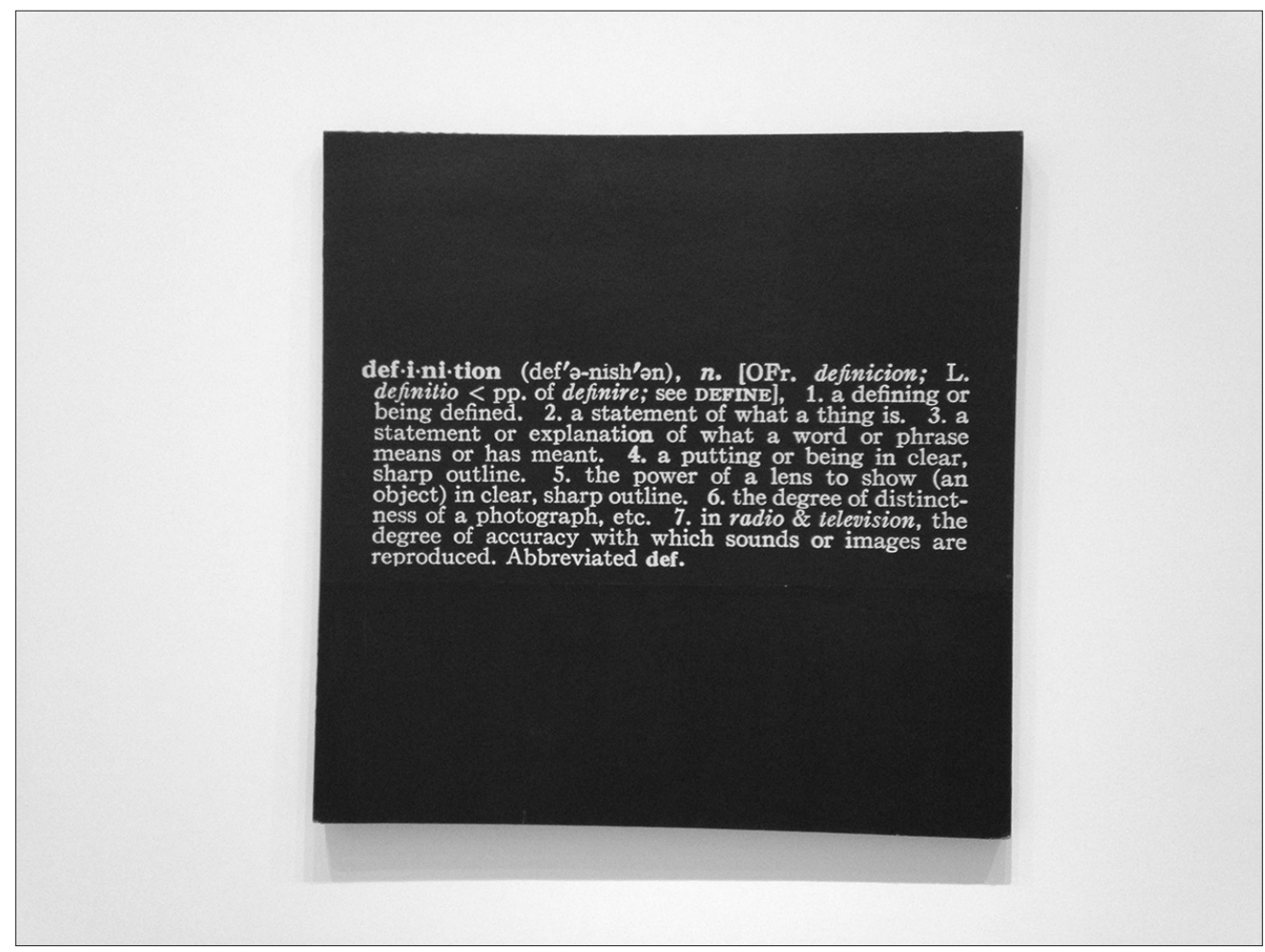

Fuente: Maurizio Pesce, commons.wikimedia.org, 〈https://commons.wikimedia.org/wiki/File:Joseph Kosuth-_Titled_(Art_ad_Idea_as_Idea)_The_Word_\%22Definition\%22_(1966-68)_(8476638687).jpg>. Elaboración: Joseph Kosuth, 1966-68.

sabe que él sabe) que esas palabras ya fueron escritas por Barbara Cartland. Sin embargo, existe una solución. Él puede decir 'Como diría Barbara Cartland, te amo locamente'. En este punto, habiendo evitado aparentar falsa inocencia, habiendo dicho claramente que ya no es posible hablar inocentemente, no obstante, él habrá dicho lo que quería decir a la mujer: que la ama, pero la ama en una era de la inocencia perdida. Si la mujer le sigue la corriente, habrá recibido una declaración de amor de todos modos. Ninguno de los dos se sentirá inocente, ambos habrán aceptado el desafío del pasado, de lo ya dicho, que no puede ser eliminado, ambos jugarán el juego de la ironía con conciencia y con placer... Pero ambos triunfarán de todos modos en su deseo de hablar de amor]. ${ }^{8}$

8. Eco, The Name of the Rose (edición para Kindle). 
La característica principal de lo posmoderno, como modo de operar, es que se puede referir al amor, como a cualquier otro concepto. En ese sentido, se basa en la crítica a la modernidad, pero desde distintas ópticas y con diversas técnicas; y, por ende, con distintos resultados. Es por eso que ha sido difícil para el autor del presente trabajo el presentar un solo ejemplo que pueda concentrar en una sola imagen la estética del arte posmoderno; ya que precisamente el movimiento parte de la pluralidad de estéticas diferentes.

\section{UNA ACTITUD POSMODERNA EN EL MUNDO DEL DERECHO}

La forma de operar en clave posmoderna, en el mundo del derecho, se encuentra en todo texto que pretende cuestionar -en un uso de la ironía- la solidez teórica y conceptual de las categorías jurídicas establecidas, no con el ánimo de verlas destruidas, sino de lograr su reconfiguración posterior; o, al menos, la conciencia respecto de la falta de solidez con la que operan.

Un gran ejemplo de este tipo de trabajo, en el ámbito del Derecho internacional -y que, mutatis mutandis, podría ser trasladado a otros ámbitos del discurso jurídico, como el Derecho constitucional- se halla en la obra de Martti Koskenniemi. ${ }^{9}$ El autor propone una forma de entender el Derecho internacional -producto del Iluminismo, en tanto época en que el Occidente perdió la fe en la existencia de un orden natural, entre los pueblos, naciones y soberanos; $y$, por lo tanto, la cuna del positivismo jurídico $-^{10}$ como un lenguaje profesional, de estructura dialéctica y contenido indeterminado, en el que intervienen argumentos contrapuestos. Dichos argumentos se basan en exigencias de concreción -en tanto, distanciamiento de las teorías de justicia natural-, ${ }^{11} \mathrm{y}$ normatividad -en tanto distanciamiento del mero comportamiento de los sujetos cuya conducta es regulada $-{ }^{12}$ del derecho, las cuales son a la vez simultáneas y mutuamente

9. Martti Koskenniemi, The politics of international law (Oxford: Hart Publishing, 2011).

10. Josep Aguiló Regla, "Sobre la constitución del estado constitucional", Doxa, n. ${ }^{\circ} 24$ (2001): 435-7, ‘https:// doi.org/10.14198/DOXA). El autor señala: "El positivismo jurídico, en general, o el positivismo como enfoque, suele caracterizarse a partir de las dos siguientes tesis: la tesis de las fuentes sociales del Derecho y la tesis de la separación conceptual entre Derecho y moral". Para las diversas acepciones de positivismo jurídico, ver Norberto Bobbio, Iusnaturalismo y positivismo jurídico, ed. por Andrea Greppi (Madrid: Trotta, 2015), 101-21.

11. Martti Koskenniemi, "Between Apology and Utopia: The Politics of International Law", en The Politics of International Law (Oxford: Hart Publishing, 2011), 38.

12. Ibíd., 38. 
excluyentes, por lo que acercarse a una implica alejarse de la otra. ${ }^{13}$ En tal contexto, la función principal del discurso jurídico es el desconocer al argumento contrario como no jurídico - $\mathrm{o}$, lo que es lo mismo, como político-, ya acusándolo de ser una mera apología del uso del poder, ya por ser expresión de un idealismo utópico. ${ }^{14} \mathrm{El}$ argumento formulado en dichos términos, sin embargo, recurrirá al mismo lenguaje, por lo que al hallarse en el mismo sistema, será susceptible de ser rebatido del mismo modo. ${ }^{15}$ Con el modelo precedente, el autor busca explicar las grandes dicotomías que "... [no aparecen como solubles de forma permanente]", como "['positivismo'/'naturalismo', 'consentimiento'/'justicia', 'autonomía'/comunidad', 'proceso'/'regla', etc.]”. ${ }^{16}$

Al exponer la estructura del discurso jurídico de este modo, el autor intenta, en sus propias palabras, mostrar que su defensa basada en los ideales del imperio del derecho ${ }^{17}$ "tenuemente esconde de la vista el hecho que el conflicto social debe todavía ser resuelto por medios políticos y que aunque exista una retórica jurídica común entre los abogados [...], esta retórica debe, por razones internas al ideal mismo, depender de principios - políticos- esencialmente disputados para justificar resultados de las disputas". 18

Ante la imposibilidad del lenguaje jurídico de ser a la vez totalmente concreto y totalmente normativo, el autor identifica cuatro posibles estructuras doctrinarias "distintivamente modernas", que se expresan en diferentes actitudes respecto del derecho,

13. Ibíd., 39.

14. Ibíd., 35 .

15. Ibíd., 40.

16. Ibíd., 39. El texto original, en idioma inglés, señala: "Different doctrinal and practical controversies turn out as transformations of this dilemma. It lies behind such dichotomies as 'positivism'/'naturalism', 'consent'/'justice', 'autonomy'/'community', 'process'/ 'rule', etc., and explains why these and other oppositions keep recurring and do not seem soluble in a permanent way".

17. Koskenniemi, "Between Apology and Utopia: The Politics of International Law". El autor recurre a la expresión anglosajona "rule of law", que ha sido traducida en varios instrumentos internacionales como su contraparte romano-germánica Rechstaat (Estado de derecho). No obstante, no es un asunto pacífico el considerar esa traducción como exacta. Ello, mucho menos en el contexto internacional, en el que el derecho que lo regula no emana de la construcción de un "Estado". Para una muestra de las dificultades de traducción de los términos, ver Bartolomé Clavero, "Imperio de la ley y rule of law: Tópica y léxico constitucionales", en Happy constitution: cultura y lengua constitucionales, Colección Estructuras y procesos (Madrid: Trotta, 1997), 181-236.

18. Koskenniemi, "Between Apology and Utopia: The Politics of International Law", 38. El texto original, en lengua inglesa y en el contexto del Derecho internacional, señala: “... our inherited ideal of a World Order based on the Rule of Law thinly hides from sight tne fact that social conflict must still be solved by political means and that even though there may exist a common legal rhetoric among international lawyers, that rhetoric must for reasons internal to the ideal itself, rely on essentially contested -political-principles to justify outcomes to international disputes". 
en relación a las cuales afirma que no existe la posibilidad de asumir un punto medio, sin incurrir en profundas aporías.

Primero están quienes defienden una aproximación regulativa -rule approach-, que enfatiza en la capacidad del derecho de oponerse a la práctica de los sujetos obligados; y, por tanto, coercionarlos. Este enfoque "piensa" el derecho en términos de reglas e insiste en un "test formal del pedigrí", determinado por el sistema de fuentes, que sirve de parámetro de validez. Desde esta aproximación, las distinciones entre derecho "duro" y "suave", reglas y principios, normas regulares y jus cogens, no son bien acogidas, porque minan la objetividad y verificabilidad del derecho. ${ }^{19}$ Esta posición doctrinaria es identificable con lo que ha sido denominado el positivismo normativista, y en nuestro examen desde el arte, guarda relación con las fuentes de inspiración en la razón, la recurrencia a las ideas republicanas del período clásico y, en general, a la estética del neoclasicismo.

Koskenniemi identifica dos críticas principales a esta aproximación: en primer lugar, la imposibilidad de excluir las consideraciones políticas en la aplicación del "test de pedigrí", por cuestiones de indeterminación del lenguaje, como las señaladas por Hart. ${ }^{20}$ En segundo lugar, señala que la propia búsqueda de una teoría pura del derecho, en su esfuerzo por hallar consistencia lógica y completa autonomía ontológica, corre el riesgo de anular su aplicabilidad en el mundo real. ${ }^{21}$

Segundo, identifica una posición que se establece sobre las críticas formuladas contra la aproximación regulativa, y la denomina como aproximación política -policy approach-. Esta aproximación, influenciada por el realismo jurídico, tiene expresiones como la "escuela de los procesos" y la "elección racional". Quienes defienden esta postura sostienen que el derecho es relevante en la medida en que se basa en el contexto de la política de los actores regulados, y que la fuerza vinculante del derecho no es más que una "ilusión jurídica". En este caso, es la efectividad-entendida como la capacidad para obtener metas sociales- la que determina la cuestión relevante en términos de definir al derecho. ${ }^{22}$ La aproximación de política, como ya ha sido señalado, es asimilable con las diversas corrientes del realismo jurídico, y por su asimilación del derecho "relevante" con la realidad, es semejante al realismo artístico -el cual tiende a la asimilación de arte con realidad-.

De acuerdo con el autor, esta aproximación es igual de vulnerable, ya que al enfatizar la concreción del derecho, diluye por completo su fuerza coercitiva; pues, si solo

19. Ibíd., 41.

20. Ibíd.

21. Ibíd.

22. Ibíd., 41-2. 
es derecho aquel que es efectivo, solamente lo es en la medida en que constituya una apología al uso del poder; mientras que si se establecen "metas sociales" más allá de la efectividad propia, la aproximación política es criticable por la misma razón que la regulativa, por aparecer como basada en un "naturalismo ilegítimo", contrario al principio liberal de la subjetividad de valor, en el que se basa la igualdad como premisa posiluminista del imperio del derecho. ${ }^{23}$

Ante estas aproximaciones contrapuestas y las críticas que contra ellas existen, el autor señala que varios juristas han asumido dos posiciones. Están quienes comentan el derecho como si la fuerza vinculante y la efectividad del derecho fueran asuntos dados por sentado; y que, por tanto, se ubicarían en una posición idealista-idealist position-. La consecuencia en que el autor identifica por quienes asumen una posición idealista no es otra que la contradicción. ${ }^{24}$ En ese sentido, la posición idealista, al asumir acríticamente los mitos - o falacias- de un derecho a la vez normativo y concreto, desprovisto de consideraciones valorativas, y a la vez apto para producir resultados materiales por sí solo, puede calificarse de romántico.

Del otro lado se hallan quienes sostienen que el derecho no puede ser visto ni como puramente normativo ni como generalmente aplicado. A ellos los define como adherentes a una posición escéptica-sceptical position-. En su criterio, esta posición termina en una actitud cínica respecto del derecho. ${ }^{25}$ Siguiendo nuestro esquema basado en los períodos artísticos, la actitud cínica -y, por ende, destructiva- de quienes asumen la posición escéptica, por tener como resultado final la anulación del derecho en toda su expresión, guarda correspondencia con el vanguardismo.

Koskenniemi califica a las aproximaciones y actitudes respecto del derecho que han sido descritas en párrafos precedentes como modernas, en el sentido de que "... [se rehúsan a desarrollar su concepto del derecho en términos de una teoría material de la justicia. Cada una asume que el derecho es una creación artificial, humana, que se gesta a través de procesos sociales y que un concepto adecuado del derecho es uno que provee de una descripción fidedigna de esos procesos y de sus resultados]". ${ }^{26}$ Ante tal definición "formal" de las distintas aproximaciones al derecho, el autor resalta la imposibilidad del derecho de aportar el contenido material para decisiones o críticas a dichas deci-

23. Ibíd., 42.

24. Ibíd.

25. Ibíd.

26. Ibíd., 44. El texto original, en idioma inglés, señala: "Each of the main positions reviewed, as well as their combinations, remain distinctly modern. Each refuses to develop its concept of law in terms of some material theory of justice. Each assumes that law is an artificial, human creation which comes about through social processes and that an adequate concept of law is one which provides a reliable description of those processes and their outcomes". 
siones por sí mismo. En tal sentido, para adoptar determinada decisión en términos de cualquiera de las aproximaciones presentadas, la determinación más relevante versará respecto de un elemento que ninguna aporta; esto es, la corrección objetiva de dicha decisión; por lo que, para adoptarla, necesariamente debe recurrir a la política para llenar el vacío. ${ }^{27}$ Claro está, el derecho cumple una función en tanto lenguaje justificativo, y su gramática particular le permite producir soluciones prescriptivas a los problemas que se le presentan; sin embargo, dichas soluciones no se producen $-\mathrm{o}$ no se producen únicamente- de lo que el sistema normativo puede aportar.

Ahora bien, a pesar de que Koskenniemi enfila sus críticas contra la forma en que el derecho es conceptualizado por la teoría y visto por quienes lo practican -y en tal sentido, el autor opera en un "mundo de la inocencia perdida", en palabras de Eco-, no se deja llevar por el cinismo, el abandono y la destrucción que esta imagen podría ocasionar. En cambio, en una actitud puramente posmoderna, busca hallar mérito en el operar formalista del derecho, por medio de una "cultura del formalismo". ${ }^{28}$ Hace notar que existe una creciente tendencia de las sociedades nacionales a alejarse del imperio del derecho, en pro de "... [estándares y compromisos cada vez más flexibles y determinados por el contexto]". ${ }^{29}$ Considera que los juristas están obligados a tomar seriamente esta tendencia, pues deberían aceptar la insuficiencia del derecho para resolver "asuntos de justicia contextual", la necesidad de recurrir a campos como la política o la causalidad social o económica y la pérdida de certeza que pregonaba la concepción del derecho en la época del posiluminismo. ${ }^{30}$ Así, afirma que pasar las decisiones por el tamiz de la aceptabilidad política es el único seguro para evitar que se conviertan en una apología de la tiranía. ${ }^{31}$

El punto al que arriba Koskenniemi, sin embargo, no debe ser leído como una fuga total hacia el decisionismo político. En su artículo “"The Lady Doth Protest Too Much': Kosovo, and the Turn to Ethics in International Law”, el autor rescata que, en

27. Esta posición contrasta con la tesis de la única respuesta correcta expuesta por Ronald Dworkin, Los derechos en serio (Barcelona: Ariel, 2002).

28. Como hace notar Bobbio, Iusnaturalismo y positivismo jurídico, 83-100, existen varias "teorías del formalismo jurídico" que "no se implican recíprocamente de una manera necesaria y por lo tanto no pueden ser confundidas, o peor aún identificadas". Ellas son "la concepción legalista de la justicia (o legalismo), la teoría normativa del derecho (o normativismo), la concepción de la ciencia jurídica como dogmática y la llamada jurisprudencia por conceptos (o conceptualismo jurídico)". De las nociones precitadas, se extrae que Koskenniemi hace referencia esencialmente a la segunda de las nociones; esto es, al normativismo.

29. Koskenniemi, "Between Apology and Utopia: The Politics of International Law", 62. El texto en inglés señala: "Social theorists have documented a recent modern turn in national societies away from the Rechtstaat into a society in which social conflict is increasingly met with flexible, contextually determined standards and compromises".

30. Ibíd., 62.

31. Ibíd. 
situaciones en que el poder hace uso de la ética y la moral como políticas de imposición de sus postulados,

la insistencia en reglas, procesos y toda la cultura del formalismo se convierte en una estrategia de resistencia y de esperanza democrática. ¿Por qué? Porque el formalismo se trata precisamente de establecer límites a los impulsos -'morales' o no- de aquellos en posición de tomar decisiones con el objeto de satisfacer intereses generales en lugar de particulares; porque proyecta a quienes toman decisiones como responsables frente a la comunidad política; y, porque reconoce las demandas efectuadas por otros miembros de la comunidad y crea la expectativa de que serán tomadas en cuenta. ${ }^{32}$

El autor ve la potencialidad del formalismo, a pesar de refutar que de algún modo pueda determinar los resultados políticos en términos del contenido de la decisión, en constituir un "horizonte de universalidad", enclavado en una "cultura de la contención", un "compromiso a escuchar las demandas de los otros". ${ }^{33}$

No obstante, el formalismo en la era de la inocencia perdida -esto es, aquel que sabe que el derecho es un modo de dominación, "que descansa en la creencia de la legalidad de ordenaciones estatuidas y de derechos de mando de los llamados por esas ordenaciones a ejercer autoridad", en palabras de Weber $-^{34}$ no desconoce que el derecho en la modernidad no es el mismo, sino que -a su juicio-, debe abandonar su vana esperanza en la razón neutral y objetiva, y reemplazarla por la experiencia política y el compromiso utópico que articulan una cultura, definida como "... [las prácticas sedimentadas que constituyen el marco normativo de cierta sociedad]". ${ }^{35}$ En la cultura del formalismo, no basta con escuchar a los otros, en sentido político, sino también incluir en la lucha cuestiones sobre quién puede efectuar las demandas y cuáles de esas demandas deben ser consideradas. Así, su propuesta se basa en un "formalismo autorreflexivo", consciente de su propia subjetividad, carácter emotivo;

32. Martti Koskenniemi, “'The Lady Doth Protest Too Much': Kosovo and the Turn to Ethics in International Law", en The Politics of International Law (Oxford: Hart Publishing, 2011), 128. El texto en inglés señala: insistence on rules, processes, and the whole culture of formalism now turns into a strategy of resistance, and of democratic hope. Why? Because formalism is precisely about setting limits to the impulses -'moral' or not- of those in decision-making positions in order to fulfil general, instead of particular, interests; because it casts decision-makers as responsible to the political community; and because it recognises the claims made by other members of that community and creates the expectation that they will be taken account of.

33. Ibíd., 128.

34. Max Weber, Economía y sociedad: Esbozo de sociología comprensiva, 4. ${ }^{\mathrm{a}}$ ed., editado por Johannes Winckelmann (Madrid: Fondo de Cultura Económica, 2002), 172.

35. Koskenniemi, "The Lady Doth Protest Too Much": Kosovo and the Turn to Ethics in International Law", 129. El texto en inglés señala: "sedimented practices constituting the normative framework of a certain society". 
y, por eso mismo, reimaginado como un compromiso con la resistencia y la transgresión. ${ }^{36}$ Culmina al señalar lo siguiente: "[Habiendo aprendido su lección, el formalismo podría re-entrar al mundo con la seguridad de que, ante cualquier lucha que tenga que afrontar, la ansiedad interna del Príncipe es menos un problema que resolver que un objetivo que alcanzar]", 37

Esta mirada posmoderna del derecho hace un fuerte uso de la ironía para cuestionar el pasado -representado por la aparentemente irreconciliable batalla entre el positivismo y el realismo, ocasionada a su vez por la "extracción de los valores", operada por el Iluminismo-, con el objeto de reconstituirlo y hacer de él algo que sea útil, por reconocer sus propias limitaciones, pero también sus potencialidades.

\section{¿LA ACTITUD POSMODERNA DE KOSKENNIEMI ES VIABLE EN EL DERECHO INTERNO?}

Ante la descripción efectuada, es factible preguntarnos si el trabajo de Koskenniemi, nacido de la reflexión sobre el contexto internacional, es replicable en el ámbito del derecho interno. Es importante reconocer que el discurso del Derecho internacional halla como premisa capital la inexistencia de ciertas características propias del Estado de derecho como un demos, que -de modo más o menos acercado a la ficción político-filosófica- actúe como soberano, o una constitución que sirva de parámetro para evaluar la validez del ordenamiento jurídico, o la presencia de un solo orden normativo jerarquizado, al que todos los sujetos se sometan de forma simultánea.

Ahora bien, las dos aproximaciones descritas en párrafos anteriores pueden ser encontradas en el ámbito de la teoría general del derecho. Josep Aguiló lo plantea del siguiente modo:

Entendido como teoría, es decir [...] como respuesta, pueden distinguirse [...] dos grandes modelos que son el resultado de interpretar de maneras diferentes las regularidades de conducta observadas: uno es el que podríamos llamar "positivismo predictivista" (que incluiría el realismo jurídico, pero no solo a él: algunas concepciones imperativistas del Derecho comparten los rasgos aquí tomados como relevantes), y otro, el positivismo normativista. La clave para distinguir entre ellos está en cómo interpretan estas regularidades de conducta y las expectativas que de ella se derivan. Si ellas permiten emitir simplemente juicios

36. Ibíd.

37. Ibíd. El texto original en inglés señala: "Having learned its lesson, formalism might then re-enter the world assured that whatever struggles it will have to weigh, the inner anxiety of the Prince is less a problem to resolve than an objective to achieve". 
fácticos en términos de probabilidad de conducta; o si, por el contrario, dan lugar a juicios normativos en términos de conducta debida [...]. Es decir, todo el positivismo normativista ha versado sobre la combinación de los principios de efectividad (o 'facticidad') del Derecho y de normatividad (o "validez") del Derecho. ${ }^{38}$

La versión normativista del positivismo puede ser identificada con la aproximación regulativa, descrita en párrafos precedentes. Hans Kelsen, a quien podríamos calificar como el mayor exponente de esta aproximación, deja en claro su visión sobre el objeto de la ciencia jurídica, en su aspecto estático, o sea “...como un orden social, como sistema de normas que regulan la conducta recíproca de los hombres"; así como dinámico, esto es, “...en su movimiento en la serie de actos por los cuales es creado y luego aplicado".39

La versión predictivista, en cambio, corresponde a la aproximación política. Ahora bien, en el ámbito interno -en el que existe una centralización del ejercicio del poder-, debe diferenciarse la conducta del gobernante de la de los gobernados. En el primer caso, encontramos, por ejemplo, a Schmitt, quien "...sostiene que un orden jurídico reposa sobre una decisión y no sobre una norma"; y que "...arremete contra la metodología kelseniana, y en particular contra el postulado neokantiano, de que la ciencia construye su propio objeto, que en la teoría kelseniana, según el jurista alemán, expulsa toda referencia a los problemas reales". ${ }^{40}$ Bobbio identifica otra expresión de la aproximación como una dirección de la polémica antipositivista, en Italia “...según la cual el derecho positivo -considerado en su acepción más restringida como derecho puesto por fuentes formales- es colocado al lado de un derecho diferente, como es el que emana directamente del comportamiento de los sujetos (el llamado 'derecho espontáneo')", 41

Existiendo aproximaciones teóricas ampliamente utilizadas en el Derecho constitucional que se ajustan a aquellas descritas, es dable pensar que la posición idealista y la escéptica -así como las correspondientes actitudes, romántica y cínica- respecto del derecho, se reproducen también en este orden. Así, habrá juristas que defenderán el derecho positivo como completo y susceptible de proveer por sí solo respuesta a los problemas sociales; mientras que otros estudiosos del derecho y -en mayor medida-

38. Aguiló Regla, "Sobre la constitución del Estado constitucional", 436-7.

39. Hans Kelsen, Teoría pura del derecho, 4. ${ }^{\mathrm{a}}$ ed. (Buenos Aires: Eudeba, 2010), 31, 〈http://site.ebrary.com/ $\mathrm{id} / 10378445$ ).

40. Carlos Miguel Herrera, "La polémica Schmitt-Kelsen sobre el guardián de la constitución”, Revista de Estudios Politicos (Nueva Época), n. ${ }^{\circ} 86$ (1994): 198-9. El autor hace referencia a la visión que Schmitt presenta en su Teología Política.

41. Bobbio, Iusnaturalismo y positivismo jurídico, 101. 
de otras ciencias sociales, lo desdeñarán como un intento fatuo por regular un poder político y un conglomerado social que actúan de acuerdo con sus propios intereses y expectativas.

Ahora bien, de la época en la que Kelsen y Schmitt expusieron su posición a la actualidad han existido cambios sensibles en el objeto de estudio del derecho. De hecho, como lo plantea Ferrajoli, la adopción como normas constitucionales de los "conceptos y valores" propios de la filosofía política -o del derecho natural- acarrea una suerte de reingreso de la axiología en el ordenamiento positivo, como principia iuris et in iure, y no únicamente como principia iuris tantum; ${ }^{42}$ lo que, a su vez, desdiría el carácter puramente formal del derecho en este contexto particular. Más aún, como el autor italiano lo afirma, la positivización de los principios se da al más alto nivel jerárquico del orden jurídico, lo que los propulsa a constituir los elementos del test de pedigrí de validez jurídica, pero ahora en sentido material y no meramente formal. ${ }^{43}$ El autor postula a la teoría del derecho como el

punto de encuentro entre las diferentes aproximaciones al estudio del derecho, a las que brinda un aparato conceptual en buena medida común: entre el doble punto de vista jurídico interno propio de las disciplinas dogmáticas positivas, el punto de vista empírico externo propio de la sociología del derecho y el punto de vista axiológico externo propio de la filosofía de la justicia. ${ }^{44}$

No obstante, este fenómeno de constitucionalización, percibido por Ferrajoli como una apertura del derecho a otras ciencias, nos parece otra versión de la aproximación regulativa $-\mathrm{y}$, en tal sentido, una nueva forma de positivismo-, solamente que ahora, basada en un derecho positivo constitucionalizado. Esto, pues el autor retoma la confianza en la teoría del derecho -positivo-, por el solo hecho de haber incorporado normas que podrían considerarse como una moral positivada. No obstante, la propia indeterminación de sus contenidos, que se ve acrecentada por no constituir una mera indeterminación lingüística, sino además axiológica en sí misma. Por tanto, la noción de Ferrajoli podría caer en el romanticismo del que hemos discurrido en párrafos precedentes.

Es más, de consentir de forma acrítica en que la incorporación de principios constitucionales en el ordenamiento implica un reingreso de la moral en el derecho, puede traer consecuencias nocivas. ${ }^{45}$ Esto puede llevar precisamente a los riesgos que hacen

42. Luigi Ferrajoli, Principia Iuris. Teoría del derecho y de la democracia, vol. 1 (Madrid: Trotta, 2007$), 38$.

43. Ibíd.

44. Ibíd., 39.

45. Bobbio, Iusnaturalismo y positivismo jurídico, 84. El autor habla desde sus años respecto del asunto del 
necesaria la cultura de formalismo como mecanismo de freno de la arbitrariedad en el ejercicio del poder -el cual no es sino el ideal defendido por el constitucionalismo-. Las distintas interpretaciones sobre el contenido del término igualdad, la necesidad de establecer soluciones de satisfacción relativa por medio de métodos como la ponderación o la proporcionalidad, o la posibilidad de justificar una medida regresiva en términos del contenido material de un derecho, pueden servir de ejemplos de la indeterminación axiológica, la cual hace que las decisiones que se adopten vuelvan a depender de opciones políticas -no abiertamente aceptadas como tales-, y que los asuntos a resolver se transformen en la justicia contextual a la que se refiere Koskenniemi. El derecho, entonces, vuelve a encerrarse en la dicotomía entre concreción y normatividad, y no incorpora en sí mismo las soluciones materiales; sino, como máximo, líneas por las que debe discurrir el argumento político, disfrazado con ropajes de razón jurídica objetiva. Tan es así que los propios principios, en tanto contenidos materiales de la Constitución, pueden ser -y, de hecho, son- utilizados por el poder político y económico como justificación para oprimir, excluir y anular las aspiraciones de dignidad de quienes son más débiles, ya que la relajación de las reglas opera en doble vía. ${ }^{46}$

Como he sostenido en un trabajo precedente, el cumplimiento de las formas en las actuaciones regidas por la Constitución -como, por ejemplo, el procedimiento

siguiente modo: "La rebelión contra [el formalismo], a la cual asistimos hoy, no es más que un momento normal en el cambio alternado de los estudios jurídicos: aquellos que por razón de su edad cabalgan sobre dos generaciones y que han vivido, por ello, los días fastos y nefastos del tecnicismo, no se maravillan; más bien irguiéndose para contemplar el proceso histórico en su movimiento complejo y variado, han aprendido a cuidarse de los ardores demasiado iconoclastas, de las impaciencias demasiado vehementes, de las esperanzas demasiado confiadas. Su tarea en la actualidad puede consistir en procurar que en la reacción contra el pasado no se pierda aquello que era válido, digno de ser conservado; evitar que por odio a cualquier exceso se quiera recomenzar todo desde el principio, y que por amor a lo nuevo por lo nuevo, se presente como descubrimiento lo que es simplemente exhumación".

46. Un ejemplo de esto nos lo provee el decreto ejecutivo n. ${ }^{\circ} 872$ de 2011, en el que el presidente de la República declaró el estado de excepción en la Función Judicial “...a fin de resolver la situación crítica por la que atraviesa y garantizar en debida forma el derecho a la justicia contemplado en la Constitución de la República y prevenir una inminente conmoción interna”. Con base en dicho decreto, el Ejecutivo realizó actos que bien podrían haber sido considerados como injerencias en el ámbito de independencia externa de la Función Judicial; sin embargo, la justificación utilizada no fue otra que el garantizar un derecho constitucional. Ver Corte Constitucional del Ecuador, Caso 008-11-DEE-CC, n. ${ }^{\circ}$ 0010-11- EE (29 de septiembre de 2011); otro ejemplo lo aporta el "Código Orgánico Integral Penal”, Pub. L. n. ${ }^{\circ}$ Suplemento del Registro Oficial 180 (2014), artículo 176. En dicha disposición, el legislador hace un parafraseo del contenido del artículo 11, número 2 de la Constitución de la República para crear un tipo penal extremadamente extenso, que abarca una gran cantidad de actividades con distintos grados de lesión al derecho a la igualdad, y les asigna una pena que no guarda relación con la cantidad de posibilidades fácticas que se adecuan al tipo. Esta disposición, consistente en una ampliación del punitivismo basada en el lenguaje de los derechos es, a manos del poder, una herramienta de opresión más que de emancipación. 
legislativo-, en tanto mecanismo para lograr la aceptabilidad política de las decisiones adoptadas, no puede ser desdeñado como un elemento secundario o caduco, al momento de determinar la conformidad de dichas decisión con el texto constitucional, como parecerían a veces sugerir la doctrina y la jurisprudencia imbuidas por la preeminencia de lo material sobre lo formal. ${ }^{47}$ Muy por el contrario, el cumplimiento de las formas es una expresión del debido proceso en su acepción más amplia -en tanto seguro en contra de la arbitrariedad en el uso del poder-, así como una garantía del principio democrático -el cual demanda la maximización de las oportunidades de participación y debate de la ciudadanía en la toma de decisiones-. Tal noción de formalismo, aunada con la experiencia política y el compromiso utópico que le otorgan el operar en el contexto de una cultura nacida en la era de la inocencia perdida, puede ser una herramienta potente ante la indeterminación de la concepción material de justicia que presenta el derecho positivo constitucionalizado. Así, la cultura de formalismo se mantiene como una propuesta para recurrir al derecho como herramienta para identificar y resistir los embates del poder y sentarlo a la mesa a justificar, en las mismas condiciones, las razones políticas de su decisión.

\section{CONCLUSIÓN}

En el presente trabajo he discurrido sobre la utilidad de pensar el derecho con una actitud posmoderna. El examen crítico del fenómeno jurídico, no con el objeto de abandonar las esperanzas en él, sino de reconocer sus limitaciones y sus potencialidades es vital. Es una labor complicada desde el punto de vista epistemológico, ya que implica definir de forma precisa el objeto de estudio -el cual puede ser este en su conjunto, o determinado fenómeno en específico-; examinar a fondo y de forma crítica todos los elementos del fenómeno, hasta encontrar sus aporías; encontrar las causas y consecuencias de las inconsistencias y contradicciones encontradas; $y$, sobre todo, no ceder ante la tentación de quedarnos en la inocencia acrítica, o abandonarnos

47. Daniel Gallegos Herrera, "El control formal de constitucionalidad de actos normativos", en Manual de justicia constitucional ecuatoriana, ed. por Jorge Benavides Ordóñez y Jhoel Escudero Soliz (Quito: Corte Constitucional del Ecuador, Centro de Estudios y Difusión, 2013), 324-33. En el artículo se analiza la sentencia de la Corte Constitucional del Ecuador, Caso 001-10-SIN-CC, n. ${ }^{\circ} 0008-09-I N$ y 0011-09-IN (18 de marzo de 2010), en la que la Corte Constitucional, para resaltar la importancia de la consulta prelegislativa en el procedimiento de aprobación de las leyes que afecten a comunidades, pueblos y nacionalidades indígenas, señaló que “...no se trata de un mero procedimiento o formalidad. En efecto, a juicio de [la] Corte $[. .$.$] , la consulta prelegislativa constituye un derecho constitucional de carácter colectivo". Esto,$ como si el contenido de un derecho constitucional no pudiere hacer referencia a la forma en que se debe dar determinado procedimiento. 
en el cinismo destructivo. En el presente trabajo, se muestra una propuesta de reconstrucción del formalismo jurídico como herramienta de resistencia y cuestionamiento al uso del poder, camuflado tras el discurso de la intervención por razones de orden moral y ética. En ese sentido, es una forma de hablar de derecho, jugando el juego de la ironía. La actitud posmoderna, sin embargo, puede producir muchas más formas de "hablar de amor en el mundo de la inocencia perdida".

\section{BIBLIOGRAFÍA}

Aguiló Regla, Josep. "Sobre la constitución del Estado constitucional”. Doxa, n. 24 (2001): 429-57. 〈https://doi.org/10.14198/DOXA〉.

Bobbio, Norberto. Iusnaturalismo y positivismo jurídico, editado por Andrea Greppi. Madrid: Trotta, 2015.

Clavero, Bartolomé. "Imperio de la ley y rule of law: Tópica y léxico constitucionales”. En Happy constitution: cultura y lengua constitucionales. Madrid: Trotta, 1997.

Courbet, Gustave. Hombre desesperado. circa de 1843 . Óleo en lienzo, $45 \times 54 \mathrm{~cm}$. Colección privada. 〈https://commons.wikimedia.org/wiki/File:Gustave_Courbet_Le_D $\%$ C3\%A9sesp $\%$ C3\%A9r\%C3\%A9.JPG〉.

Delacroix, Eugène. La libertad guiando al pueblo. 1830. Óleo en lienzo, $260 \times 325 \mathrm{~cm}(102.4$ $\times 128$ in). Museo del Louvre. 〈https://commons.wikimedia.org/wiki/File:Eug\%C3\%A8ne_ Delacroix_-_Le_28_Juillet._La_Libert\%C3\%A9_guidant_le_peuple.jpg).

Deschamps, Christian. Quarante ans de philosophie en France: la pensée singulière, de Sartre à Deleuze. Philosophie présente. París: Bordas, 2003.

Dworkin, Ronald. Los derechos en serio. Barcelona: Ariel, 2002.

Eco, Umberto. The Name of the Rose, traducido por William Weaver. Boston: Houghton Mifflin Harcourt, 2011. 〈http://banq.lib.overdrive.com/ContentDetails.htm?id=DA9EF467-F6334484-8023-B4B0121CD78C).

Ecuador. Código Orgánico Integral Penal. Suplemento del Registro Oficial 180 de 2014.

Ecuador Corte Constitucional del Ecuador. Caso 001-10-SIN-CC, n. ${ }^{o}$ 0008-09-IN y 0011-09IN. 18 de marzo de 2010.

-. Caso 008-11-DEE-CC, n. ${ }^{\circ}$ 0010-11-EE. 29 de septiembre de 2011.

Ferrajoli, Luigi. Principia Iuris. Teoría del derecho y de la democracia, vol. 1. Madrid: Trotta, 2007.

Gallegos Herrera, Daniel. "El control formal de constitucionalidad de actos normativos". En Manual de justicia constitucional ecuatoriana, editado por Jorge Benavides Ordóñez y Jhoel Escudero Soliz, 324-33. Quito: Corte Constitucional del Ecuador, Centro de Estudios y Difusión, 2013.

Herrera, Carlos Miguel. "La polémica Schmitt-Kelsen sobre el guardián de la Constitución”. Revista de Estudios Politicos (Nueva Época), n. ${ }^{\circ} 86$ (1994). 
Kelsen, Hans. Teoría pura del derecho. 4. ${ }^{\mathrm{a}}$ ed. Buenos Aires: Eudeba, 2010. «http://site.ebrary. com/id/10378445>.

Koskenniemi, Martti. "Between Apology and Utopia: The Politics of International Law”. En The Politics of International Law, 35-62. Oxford: Hart Publishing, 2011.

—. "The Lady Doth Protest Too Much: Kosovo and the Turn to Ethics in International Law". En The Politics of International Law, 112-30. Oxford: Hart Publishing, 2011.

—. The politics of international law. Oxford: Hart Publishing, 2011.

Kosuth, Joseph. "Titled (Art as Idea as Idea) The Word "Definition". 1966-68. «https://commons.wikimedia.org/wiki/File:Joseph_Kosuth-_Titled_(Art_ad_Idea_as_Idea)_The_ Word_\%22Definition\%22_(1966-68)_(8476638687).jpg>.

Picasso, Pablo. "Les Demoiselles d'Avignon.Jpg". Wikipedia, 31 de mayo de 2017. 〈https://en.wikipedia.org/w/index.php?title=File:Les_Demoiselles_d\%27Avignon. jpg\&oldid=783122160>.

Ribera, Juan Antonio de. Cincinato abandona el arado para dictar leyes a Roma. 1806. Óleo en lienzo, 160x215 cm. Museo del Prado. 〈https://commons.wikimedia.org/wiki/ File:Cincinato_abandona_el_arado_para_dictar_leyes_a_Roma,_c.1806_de_Juan_Antonio_Ribera.jpg>.

Semenzato, Camillo. El mundo del arte. Barcelona: Grijalbo, 1978.

Weber, Max. Economía y sociedad: esbozo de sociología comprensiva, editado por Johannes Winckelmann. 4. ${ }^{\mathrm{a}}$ ed. Madrid: Fondo de Cultura Económica, 2002. 